\title{
The prevalence of eating behaviors among Canadian youth using cross-sectional school-based surveys
}

Heather G Lillico ${ }^{1}$, David Hammond ${ }^{1 *}$, Steve Manske ${ }^{2}$ and Donna Murnaghan ${ }^{3}$

\begin{abstract}
Background: Obesity is a growing public health concern in Canada. Excess weight is particularly a concern among youth given that obesity in youth predicts obesity in adulthood. Eating behaviors, both inside and outside the home have been associated with increased risk of obesity; however, there is little data among Canadian youth to monitor trends.
\end{abstract}

Methods: The School Health Action, Planning and Evaluation Surveys (SHAPES) were administered in schools. Our study examined 20, 923 students (grades 5-12) from four regions in Canada. The regions were Hamilton and Thunder Bay (both in Ontario), the Province of Prince Edward Island, and the Province of Quebec.

Results: Consuming breakfast daily was reported by $70 \%$ of grade $5-8$ students, and $51 \%$ of grade 9-12's. Among students in grade $9-12,52 \%$ reported eating with family members daily, compared with $68 \%$ in grade $5-8$. Just over half of students in grade 5-8, and 70\% in grade 9-12 reported eating at a fast-food place once a week or more. Among grade 5-8 students 68\% reported eating in front of the television at least once per week, compared to $76 \%$ in grade $9-12$. Obese students were more likely to watch TV while eating, and less likely to eat with a family member and eat breakfast.

Conclusions: The findings suggest that only a modest proportion of youth report dietary patterns that have previously been associated with healthy eating and reduced risk of obesity. Later adolescence may be a critical time for intervention in health-related behaviors.

Keywords: Obesity, Adolescent, Eating habits

\section{Background}

The prevalence of overweight and obese youth is a growing public health concern in Canada. According to the Canadian Health Measures Survey 2009-2011, approximately $20 \%$ of youth aged $12-17$ are overweight, and $10 \%$ are obese [1]. Excess weight is particularly a concern among children and youth as obesity during this period is associated with obesity during adulthood [2]. Excess weight is also a risk factor for cardiovascular disease, type 2 diabetes, high blood pressure, osteoarthritis, gallbladder disease, and certain cancers [3]. There is evidence to suggest that certain eating patterns affect diet quality, energy intake and/or weight.

\footnotetext{
* Correspondence: dhammond@uwaterloo.ca

${ }^{1}$ School of Public Health \& Health Systems, University of Waterloo, 200

University Avenue West, Waterloo, Ontario N2L 3G1, Canada

Full list of author information is available at the end of the article
}

\section{Skipping breakfast}

Excess energy intake is a primary risk factor for obesity. Certain patterns of eating, such as skipping breakfast, have been associated with energy intake and increased weight gain [4-7]. Breakfast skipping is thought to affect weight status by increasing energy intake; not eating in the morning may lead to increased feelings of hunger and consequently overeating later in the day [6]. In addition, those who skip breakfast are more likely to consume snacks that are higher in fat, and obtain more calories from fat in their daily diet than those who eat breakfast [7]. One factor that has been shown to increase the likelihood of adolescents consuming breakfast is having a parent present in the morning [8].

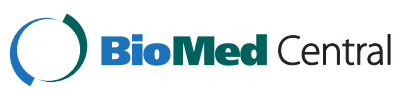

(c) 2014 Lillico et al.; licensee BioMed Central Ltd. This is an Open Access article distributed under the terms of the Creative Commons Attribution License (http://creativecommons.org/licenses/by/2.0), which permits unrestricted use, distribution, and reproduction in any medium, provided the original work is properly credited. 


\section{Eating meals with family members}

Eating meals with family members has also been associated with healthier diet. A systematic review in 2008 reported that $25-57 \%$ of adolescents ate meals with their family five or more times per week, and that the number of family meals decreases with age [9]. A five-year longitudinal study of middle-school and high-school students found that eating family meals was associated with improved dietary intake, and better psychological wellbeing; however, no consistent associations were observed with obesity [10]. The literature is inconsistent as to the effect of family meals on weight status. In a longitudinal Canadian study, family meals were associated with a lower BMI in female adolescents, but not males [11]. In another study an inverse association was found between eating meals together and overweight status crosssectionally; however, after three years of follow-up there was no longitudinal association between the likelihood of becoming overweight and consuming meals with family members [12]. In another study, family dinners were associated with an increase in servings of fruits or vegetables, but having the television on during these family meals was associated with a decrease in those foods, thereby negating some of the benefits of eating together [13].

\section{Fast-food consumption}

Fast-food consumption is a prevalent eating behavior that affects weight status. Estimates from a national survey conducted in 2004 indicate that one third of Canadian teenagers aged 14-18, and one quarter of all Canadians consumed food at a fast-food outlet in the last 24 hours [14]. While not all food consumed outside of the home is of poor nutritional quality, restaurants generally offer foods that have larger portions, and are higher in calories and fat [15]. Fast-food consumption is associated with increased energy intake, and increased calorie consumption from fat [16-18]. Increased consumption of sugar sweetened beverages and fried potatoes is also associated with eating fast-food $[17,19]$. The literature suggests that the odds of becoming overweight or obese increase with greater fast-food consumption [20]. Few Canadian studies address fast-food consumption among youth. One cross-sectional study found that obese individuals consumed more fast-food than non-obese children and adolescents, and that percent body fat was positively correlated with consuming food outside of the home [21]. Obese children and adolescents also consumed more grain products, and sugar sweetened drinks, than non-obese individuals. Expanding on that, another study found that grades 6-8 students in Ontario, Canada consumed higher amounts of energy, meats and alternatives and "other" foods (according to Canada's Food Guide) when they ate lunch at restaurants/fast-food outlets compared to eating at home/school [22]. It is also important to note that increased fast-food consumption is associated with decreased fruit and vegetable consumption $[16,17,23]$.

\section{Eating in front of the television}

Eating in front of the television has also been associated with diet quality and weight status. Diet quality is lower among children who eat in front of the TV more often; they eat less fruits and vegetables, have higher energy intakes from fat and sugar, and consume more soft-drinks [24-27]. In addition, individuals consume more calories and larger portions while eating in front of the TV [28]. Not surprisingly, watching television while eating is positively associated with BMI [29]. Liang and colleagues found that watching TV by itself, and eating while watching television were both independently associated with being overweight [24].

Given the increasing prevalence of obesity, there is a need to monitor changes in eating patterns among youth. Specifically, it is important to examine behaviors that have been shown to affect diet quality and weight status to better understand their relationship with obesity.

To date, however, there is very little evidence among Canadian youth with which to track changes over time. The specific research objectives of the current paper are to: 1) examine the frequency of the four eating behaviors: eating breakfast, eating with an adult family member, eating at a fast-food place or restaurant, and eating in front of the television, and 2) explore the extent to which these eating behaviors differ across socio-demographic groups and geographic regions.

\section{Methods}

\section{Participants}

Students in grade 5-12 who completed the School Health Action, Planning and Evaluation System (SHAPES) were included in the current study [30]. SHAPES surveys were conducted in four regions in Canada: 1) Hamilton, Ontario, 2) Thunder Bay, Ontario, 3) the Province of Prince Edward Island (PEI), and 4) the Province of Quebec. Respondents for whom age, sex or grade was missing or inconsistent were excluded from the analysis $(n=295)$. The Hamilton data set included grades 9-12; questionnaires were administered in 8 schools and data were collected from roughly 5,000 students. Thunder Bay data included students in grades 9-12 and were collected in 9 schools with approximately 3,000 students. The PEI data set included grades 5-12, with over 6,000 students and was collected in 54 schools, and the Quebec data set included grades $5 \& 6$, and secondary I-V, and was collected in 140 schools from approximately 9,000 students. The Healthy Eating Module (which contained 
the outcomes of interest) was not administered to all students, so 7722 participants were excluded from current data analyses for this reason.

\section{Instruments}

Data from the SHAPES were used for this study. Topics include tobacco use, physical activity, healthy eating and mental fitness [31]. Tailored results from the in-class, self-administered, machine readable questionnaire are reported back to schools after data collection [32].

Demographic variables included age (in years), grade (5-12) and sex. Self-reported height (in centimetres) and weight (in kilograms) were collected and used to calculate body mass index (BMI). The World Health Organization 2007 BMI cut-off values were used to categorize individuals into underweight, healthy weight, overweight and obese [33]. Height and weight were not asked for grades 5-8 in PEI, and grades 5-6 in Quebec and so BMI could not be computed for this sub-set of respondents.

The Healthy Eating Module asked respondents about various eating-related behaviors, including: "In a usual school week (Monday to Friday), how many times do you do the following...?" "Eat breakfast"; "Eat foods purchased at a fast-food place or restaurant"; "Eat meals while watching television"; and "Eat meals with at least one adult family member." The response options for Hamilton, Thunder Bay and PEI data collection were: none, less than once a week, 1 time, 2 times, 3 times, 4 times, 5 times, and $6+$ times per week. Quebec survey responses were: none, 1 time per week, 2 times, 3 times, 4 times, and 5+ times per week. Responses were recategorized into none, once per week or less than once per week, 2 times, 3 times, 4 times, and $5+$ times per week to standardize across surveys.

\section{Procedure}

Data for Hamilton were collected between December 2009 and April 2010, and Thunder Bay data were collected in December 2009. Data from PEI were collected November 2010 until April 2011 and Quebec data were collected between January 2011 and May 2011. Ethics approval was provided by Research Ethics Boards at the University of Waterloo and the University of Prince Edward Island, and from appropriate School Board Ethics committees. The process for consent differed depending on participant age. For students aged 14 and older, active information/passive consent was used. School personnel mailed information letters to parents. The information letter explained the nature and rationale of the survey and provided clear opportunities to decline their child's participation. Parents could call a toll-free number to ask questions about the survey, or decline participation. Permission to participate was granted if parents did not contact project/school staff. Passive consent was used to decrease burden on the schools, and the level of risk involved was deemed minimal. If parents declined participation on their child's behalf, then they could not participate. For students under the age of 14, active consent was used. Students brought a letter home which provided the nature and rationale of the survey and clearly stated that participation is voluntary. Parents were asked to indicate if they provided permission for their child to participate. Only students with returned, signed permission forms were able to participate. On the day of survey administration teachers read a standardized script that provided information about the surveys and confidentiality procedures. Students were also told that their participation was voluntary and they could refuse to participate at any time without penalty. Students who did not wish to participate were given an alternate activity. No compensation was provided for participation.

\section{Data analysis}

Descriptive statistics are reported for each of the four eating behaviors and the association between the four outcomes was examined using Pearson correlations. Separate logistic regression models were fitted to examine predictors of the four eating behaviors. Logistic regression models were used because the data was not normally distributed and did not meet assumptions for ordinal regression. Each of the outcome behaviors were dichotomized. The outcomes of eating breakfast and eating with an adult family member were both recategorized into five or more times per week and all other frequencies per week. The outcomes of eating at a fastfood place or restaurant, and eating in front of the television were recategorized into zero times per week and all other frequencies per week. Regression models were stratified by grade because BMI was not uniformly available for grades 5-8. Additionally, models were stratified by grade given the differenes between between primary and secondary school settings, including with respect to food environments within schools. The models run with younger students (grades 5-8) included three covariates: age, gender and survey location. The models run with older students (grades 9-12) included four covariates: age, gender, BMI level and survey location. Age and grade were not entered into the same model because they were highly correlated. Odds ratios are reported in all cases. Analyses were conducted using SPSS (version 20, 2011, IBM Corp., Armonk, NY).

\section{Results}

\section{Sample characteristics}

Sample characteristics are shown in Table 1. As noted above, Thunder Bay and Hamilton samples did not include grade 5-8 students. In Quebec, secondary schools end at Secondaire V, equivalent to Grade 11. 
Table 1 Sample characteristics $N=20,923$

\begin{tabular}{|c|c|c|c|c|c|c|}
\hline & $\begin{array}{c}\text { PEI } \\
n=1417\end{array}$ & $\begin{array}{c}\text { Quebec } \\
n=12246\end{array}$ & \multirow[t]{2}{*}{$\begin{array}{l}\text { Hamilton } \\
n=2541\end{array}$} & $\begin{array}{c}\text { Thunder bay } \\
n=1499\end{array}$ & $\begin{array}{c}\text { PEI } \\
\mathrm{n}=1812 \\
\end{array}$ & \multirow[t]{2}{*}{$\begin{array}{c}\text { Quebec } \\
n=1048\end{array}$} \\
\hline & \multicolumn{2}{|c|}{ Grade 5-8 } & & \multicolumn{2}{|c|}{ Grade $9-12$} & \\
\hline \multicolumn{7}{|l|}{ Age } \\
\hline 11 or under & $46.5 \%$ & $67.9 \%$ & - & - & - & - \\
\hline 12 & $25.9 \%$ & $23.3 \%$ & - & - & - & $0.1 \%$ \\
\hline 13 & $23.7 \%$ & $5.8 \%$ & $0.3 \%$ & $1.9 \%$ & $0.9 \%$ & - \\
\hline 14 & $3.8 \%$ & $2.5 \%$ & $23.3 \%$ & $32.4 \%$ & $20.7 \%$ & $16.5 \%$ \\
\hline 15 & $0.1 \%$ & $0.4 \%$ & $25.1 \%$ & $32.5 \%$ & $26.8 \%$ & $32.5 \%$ \\
\hline 16 & - & - & $24.7 \%$ & $24.1 \%$ & $22.8 \%$ & $32.2 \%$ \\
\hline 17 or older & - & - & $26.5 \%$ & $9.1 \%$ & $28.8 \%$ & $18.7 \%$ \\
\hline Mean & 11.9 & 11.4 & 15.5 & 15.1 & 15.6 & 15.5 \\
\hline (SD) & $(0.92)$ & $(0.75)$ & $(1.12)$ & $(1.00)$ & $(1.14)$ & (0.98) \\
\hline \multicolumn{7}{|l|}{ Grade } \\
\hline 5 & $29.6 \%$ & $50.5 \%$ & - & - & - & - \\
\hline 6 & $19.8 \%$ & $39.7 \%$ & - & - & - & - \\
\hline 7 & $24.0 \%$ & $4.9 \%$ & - & - & - & - \\
\hline 8 & $26.6 \%$ & $4.9 \%$ & - & - & - & - \\
\hline 9 & - & - & $28.9 \%$ & $35.4 \%$ & $24.0 \%$ & $36.3 \%$ \\
\hline 10 & - & - & $24.3 \%$ & $33.0 \%$ & $27.3 \%$ & $30.7 \%$ \\
\hline 11 & - & - & $24.7 \%$ & $23.8 \%$ & $24.6 \%$ & $33.0 \%$ \\
\hline 12 & - & - & $22.0 \%$ & $7.7 \%$ & $24.2 \%$ & - \\
\hline \multicolumn{7}{|l|}{ Gender } \\
\hline Female & $49.0 \%$ & $49.7 \%$ & $50.1 \%$ & $49.5 \%$ & $47.5 \%$ & $50.7 \%$ \\
\hline Male & $51.0 \%$ & $50.3 \%$ & $49.9 \%$ & $50.5 \%$ & $52.5 \%$ & $49.3 \%$ \\
\hline \multicolumn{7}{|l|}{$\mathrm{BMI}^{\mathrm{a}}$} \\
\hline Underweight & - & - & $1.6 \%$ & $1.3 \%$ & $1.0 \%$ & $1.3 \%$ \\
\hline Healthy weight & - & - & $56.6 \%$ & $53.4 \%$ & $56.1 \%$ & $62.5 \%$ \\
\hline Overweight & - & - & $11.0 \%$ & $13.7 \%$ & $15.3 \%$ & $11.6 \%$ \\
\hline Obese & - & - & $4.8 \%$ & $5.3 \%$ & $7.4 \%$ & $4.5 \%$ \\
\hline Not Stated & - & - & $26.1 \%$ & $26.3 \%$ & $20.1 \%$ & $20.1 \%$ \\
\hline
\end{tabular}

${ }^{\mathrm{a}} \mathrm{BMI}$ was not asked of grade $5-8$ students.

\section{Prevalence of eating behaviors}

Tables 2 and 3 show the prevalence of four eating behaviors among students in grade 5-8, and those in grade 9-12 for each of the four regions.

\section{Eating breakfast}

A total of $70 \%$ of students in grade 5-8 reported eating breakfast 5 times per week or more, and fewer than $5 \%$ of students reported not eating breakfast at all during the week. Among grade 9-12 students 50\% of students reported eating breakfast 5 times per week or more, and roughly $10 \%$ reported not eating breakfast at all in a typical week.

\section{Eating with an adult family member}

Just over two thirds of students in grade 5-8 reported eating meals with at least one adult family member 5 or more times per week, compared with roughly 5\% who reported not eating with an adult at all during the week. Among students in grade 9-12, just over half reported family meals 5 or more times during the week, and approximately $8 \%$ reported not eating any meals with an adult during the week.

\section{Eating at a fast-food place or restaurant}

Just over half (55\%) of students in grade 5-8 reported consuming food at a fast-food place or restaurant once a 
Table 2 Prevalence of four eating behaviors in various geographic regions (Grade 5-8)

\begin{tabular}{|c|c|c|c|}
\hline In a usual week (Monday to Friday), how often do you: & PEI $n=1417$ & Quebec $n=12246$ & Total $n=13663$ \\
\hline \multicolumn{4}{|l|}{ Eat breakfast } \\
\hline None & $3.9 \%$ & $3.4 \%$ & $3.5 \%$ \\
\hline Once/week or less & $9.2 \%$ & $9.5 \%$ & $9.5 \%$ \\
\hline 2 times/week & $5.7 \%$ & $4.1 \%$ & $4.2 \%$ \\
\hline 3 times/week & $7.2 \%$ & $5.0 \%$ & $5.3 \%$ \\
\hline 4 times/week & $6.5 \%$ & $7.3 \%$ & $7.2 \%$ \\
\hline $5+$ times/week & $67.4 \%$ & $70.7 \%$ & $70.4 \%$ \\
\hline \multicolumn{4}{|l|}{ Eat meals with at least one adult family member } \\
\hline None & $8.0 \%$ & $4.5 \%$ & $4.9 \%$ \\
\hline Once/week or less & $8.0 \%$ & $5.3 \%$ & $5.6 \%$ \\
\hline 2 times/week & $5.0 \%$ & $5.0 \%$ & $5.0 \%$ \\
\hline 3 times/week & $6.8 \%$ & $7.2 \%$ & $7.2 \%$ \\
\hline 4 times/week & $9.1 \%$ & $9.2 \%$ & $9.2 \%$ \\
\hline $5+$ times/week & $63.1 \%$ & $68.8 \%$ & $68.2 \%$ \\
\hline \multicolumn{4}{|l|}{ Eat foods purchased at a fast-food place/restaurant } \\
\hline None & $43.7 \%$ & $44.8 \%$ & $44.7 \%$ \\
\hline Once/week or less & $42.0 \%$ & $37.3 \%$ & $37.8 \%$ \\
\hline 2 times/week & $8.8 \%$ & $10.0 \%$ & $9.9 \%$ \\
\hline 3 times/week & $2.8 \%$ & $3.3 \%$ & $3.3 \%$ \\
\hline 4 times/week & $0.6 \%$ & $1.4 \%$ & $1.3 \%$ \\
\hline $5+$ times/week & $2.2 \%$ & $3.1 \%$ & $3.0 \%$ \\
\hline \multicolumn{4}{|l|}{ Eat meals while watching television } \\
\hline None & $30.3 \%$ & $32.2 \%$ & $32.0 \%$ \\
\hline Once/week or less & $27.9 \%$ & $21.6 \%$ & $22.3 \%$ \\
\hline 2 times/week & $11.6 \%$ & $13.3 \%$ & $13.1 \%$ \\
\hline 3 times/week & $9.7 \%$ & $10.3 \%$ & $10.2 \%$ \\
\hline 4 times/week & $5.9 \%$ & $6.1 \%$ & $6.0 \%$ \\
\hline $5+$ times/week & $14.5 \%$ & $16.5 \%$ & $16.3 \%$ \\
\hline
\end{tabular}

week or more, and less than half (45\%) reported not eating at a fast-food place or restaurant during the week. Among grade $9-12$ students $70 \%$ reported eating fastfood at least once a week, and 30\% said they consumed no fast-food during the week.

\section{Eating in front of the television}

Almost 70\% of students in grade 5-8 reported eating in front of the television at least once per week, while about one third reported no meals in front of the TV per week. Students in grade 9-12 reported eating in front of the television in about $75 \%$ of cases, and $25 \%$ reported not eating in front of the television during the week.

\section{Correlations between eating behaviors}

Correlations were examined between the four eating behaviors. Eating breakfast was negatively associated with eating at a fast-food place or restaurant $(\mathrm{r}=-0.066, \mathrm{p}<$
0.001), and eating while watching television $(\mathrm{r}=-0.038$, $\mathrm{p}<0.001$ ). Eating breakfast was positively associated with eating with at least one adult family member $(r=0.326$, $\mathrm{p}<0.001$ ). Eating at a fast-food place or restaurant was positively associated with eating while watching television $(\mathrm{r}=0.221, \mathrm{p}<0.001)$, but negatively associated with eating with an adult family member $(r=-0.070$, $\mathrm{p}<0.001)$. Eating while watching television was negatively associated with eating with an adult family member $(\mathrm{r}=-0.081, \mathrm{p}<0.001)$. When the analysis was stratified by grade level (grade 5-8 vs. grade 9-12), the pattern of results were the same.

\section{Correlates of eating behaviors}

Tables 4 and 5 show the results of the logistic regression models used to examine correlates of eating behaviors, while adjusting for other factors. 
Table 3 Prevalence of four eating behaviors in various geographic regions (Grade 9-12)

\begin{tabular}{|c|c|c|c|c|c|}
\hline In a usual week (Monday to Friday), how often do you: & $\begin{array}{l}\text { Hamilton } \\
\mathrm{n}=2541\end{array}$ & $\begin{array}{c}\text { Thunder bay } \\
n=1499\end{array}$ & $\begin{array}{c}\text { PEI } \\
\mathrm{n}=1812\end{array}$ & $\begin{array}{c}\text { Quebec } \\
n=1408\end{array}$ & $\begin{array}{c}\text { Total } \\
\mathrm{n}=7260 \\
\end{array}$ \\
\hline \multicolumn{6}{|l|}{ Eat breakfast } \\
\hline None & $12.2 \%$ & $11.7 \%$ & $9.5 \%$ & $7.4 \%$ & $10.5 \%$ \\
\hline Once/week or less & $15.8 \%$ & $14.4 \%$ & $12.1 \%$ & $3.6 \%$ & $12.2 \%$ \\
\hline 2 times/week & $9.5 \%$ & $7.6 \%$ & $9.1 \%$ & $5.9 \%$ & $8.3 \%$ \\
\hline 3 times/week & $10.1 \%$ & $9.6 \%$ & $9.9 \%$ & $7.4 \%$ & $9.4 \%$ \\
\hline 4 times/week & $8.8 \%$ & $8.4 \%$ & $6.7 \%$ & $9.2 \%$ & $8.3 \%$ \\
\hline $5+$ times/week & $43.7 \%$ & $48.3 \%$ & $52.7 \%$ & $66.5 \%$ & $51.3 \%$ \\
\hline \multicolumn{6}{|l|}{ Eat meals with at least one adult family member } \\
\hline None & $8.7 \%$ & $7.5 \%$ & $8.1 \%$ & $4.8 \%$ & $7.5 \%$ \\
\hline Once/week or less & $11.4 \%$ & $12.3 \%$ & $10.0 \%$ & $4.0 \%$ & $9.8 \%$ \\
\hline 2 times/week & $9.2 \%$ & $8.4 \%$ & $7.1 \%$ & $4.4 \%$ & $7.6 \%$ \\
\hline 3 times/week & $11.7 \%$ & $11.1 \%$ & $10.5 \%$ & $8.1 \%$ & $10.6 \%$ \\
\hline 4 times/week & $12.8 \%$ & $12.5 \%$ & $11.4 \%$ & $13.3 \%$ & $12.5 \%$ \\
\hline $5+$ times/week & $46.2 \%$ & $48.2 \%$ & $52.9 \%$ & $65.3 \%$ & $52.0 \%$ \\
\hline \multicolumn{6}{|l|}{ Eat foods purchased at a fast-food place/restaurant } \\
\hline None & $24.9 \%$ & $32.8 \%$ & $28.9 \%$ & $38.9 \%$ & $30.2 \%$ \\
\hline Once/week or less & $45.0 \%$ & $45.8 \%$ & $40.7 \%$ & $39.2 \%$ & $43.0 \%$ \\
\hline 2 times/week & $13.9 \%$ & $11.3 \%$ & $13.3 \%$ & $13.1 \%$ & $13.0 \%$ \\
\hline 3 times/week & $6.9 \%$ & $4.4 \%$ & $7.3 \%$ & $4.2 \%$ & $5.9 \%$ \\
\hline 4 times/week & $3.4 \%$ & $1.8 \%$ & $3.1 \%$ & $1.6 \%$ & $2.7 \%$ \\
\hline $5+$ times/week & $6.0 \%$ & $4.0 \%$ & $6.8 \%$ & $3.0 \%$ & $5.2 \%$ \\
\hline \multicolumn{6}{|l|}{ Eat meals while watching television } \\
\hline None & $20.9 \%$ & $22.5 \%$ & $24.0 \%$ & $33.1 \%$ & $24.4 \%$ \\
\hline Once/week or less & $27.8 \%$ & $25.9 \%$ & $23.2 \%$ & $20.1 \%$ & $24.8 \%$ \\
\hline 2 times/week & $16.3 \%$ & $15.5 \%$ & $13.6 \%$ & $12.5 \%$ & $14.7 \%$ \\
\hline 3 times/week & $12.7 \%$ & $14.5 \%$ & $13.8 \%$ & $10.3 \%$ & $12.8 \%$ \\
\hline 4 times/week & $6.3 \%$ & $6.3 \%$ & $8.5 \%$ & $6.5 \%$ & $6.9 \%$ \\
\hline 5+ times/week & $16.0 \%$ & $15.2 \%$ & $16.9 \%$ & $17.6 \%$ & $16.4 \%$ \\
\hline
\end{tabular}

\section{Eating breakfast}

Among grade 5-8 students, males $(\mathrm{p}<0.001)$, and younger students $(\mathrm{p}<0.001)$ were significantly more likely to eat breakfast. The model with students in grade 9-12 revealed the same pattern for age $(\mathrm{p}<0.001)$ and sex $(\mathrm{p}<0.001)$. The associations for site showed that those in Quebec were more likely to eat breakfast than those in Hamilton $(\mathrm{p}<0.001)$, PEI $(\mathrm{p}<0.001)$ and Thunder Bay $(\mathrm{p}<0.001)$. Those in PEI were more likely than those in Thunder Bay to eat breakfast $(\mathrm{p}=0.004)$. Students in Thunder Bay were more likely than those in Hamilton to eat breakfast $(p=0.03)$. Students who were obese were less likely to eat breakfast compared to healthy weight individuals $(p=0.046)$. Those who were underweight $(p=0.020)$, healthy weight $(\mathrm{p}<0.001)$, or overweight $(\mathrm{p}<0.001)$ were more likely to eat breakfast than those who did not state their height and weight.

\section{Eating with an adult family member}

Among students in grade $5-8$, older students $(\mathrm{p}=0.017)$, and those living in PEI $(\mathrm{p}<0.001)$ were less likely to eat with an adult family member. Students in grade 9-12 were less likely to eat with an adult family member as they got older $(\mathrm{p}<0.001)$. Students living in Quebec were more likely to eat with an adult family member compared to those in Hamilton $(\mathrm{p}<0.001)$, Thunder Bay $(\mathrm{p}<0.001)$, and PEI $(\mathrm{p}<0.001)$. Additionally, those in PEI were more likely than those in Thunder Bay $(\mathrm{p}<0.001)$ and Hamilton $(\mathrm{p}<0.001)$ to eat with a family member. Students who were underweight were more likely to eat with an adult compared to healthy weight $(\mathrm{p}=0.003)$, overweight $(\mathrm{p}=$ $0.002)$, and obese $(p<0.001)$ students. Additionally, underweight $(\mathrm{p}<0.001)$, and healthy weight students $(\mathrm{p}=0.002)$ were more likely to eat with an adult than those who did not state their height and weight. 
Table 4 Correlates of eating behaviors (breakfast \& family meals)

\begin{tabular}{|c|c|c|c|c|}
\hline & \multicolumn{2}{|c|}{ Eating breakfast } & \multicolumn{2}{|c|}{$\begin{array}{l}\text { Eating with an adult } \\
\text { Family member }\end{array}$} \\
\hline & Grade 5-8 & Grade $9-12^{\mathrm{a}}$ & Grade $5-8^{a}$ & Grade $9-12^{\mathrm{a}}$ \\
\hline Adjusted $\mathrm{R}^{2 \mathrm{~b}}$ & .013 & 0.062 & 0.003 & 0.038 \\
\hline \multicolumn{5}{|l|}{ Sex } \\
\hline Female (ref) vs. Male & $1.37^{* * *}$ & $1.60^{* * *}$ & 0.96 & 1.00 \\
\hline Age & $0.84^{* * *}$ & $0.90^{* * *}$ & $0.95^{*}$ & $0.86^{* * *}$ \\
\hline \multicolumn{5}{|l|}{ Site } \\
\hline PEI (ref) vs. Quebec ${ }^{c}$ & 1.089 & $1.80^{* * *}$ & $1.26^{* * *}$ & $1.66^{* * *}$ \\
\hline PEI vs. Hamilton & - & $0.70^{* * *}$ & - & $0.76^{* * *}$ \\
\hline PEI vs. TBay & - & $0.81^{* *}$ & - & $0.77^{* * *}$ \\
\hline Quebec (ref) vs. Hamilton & - & $0.39^{* * *}$ & - & $0.46^{* * *}$ \\
\hline Quebec vs. TBay & - & $0.45^{* * *}$ & - & $0.47^{* * *}$ \\
\hline Hamilton (ref) vs. TBay & - & $1.16^{* *}$ & - & 1.02 \\
\hline \multicolumn{5}{|l|}{$\mathrm{BMI}^{\mathrm{d}}$} \\
\hline Healthy Weight (ref) vs. Underweight & - & 1.20 & - & $1.97^{* *}$ \\
\hline Healthy Weight vs. Overweight & - & 0.95 & - & 0.97 \\
\hline Healthy Weight vs. Obese & - & $0.81^{*}$ & - & 0.83 \\
\hline Healthy Weight vs. Not Stated & - & $0.73^{* * *}$ & - & $0.84^{* *}$ \\
\hline Not Stated (ref) vs. Underweight & - & $1.65^{*}$ & - & $2.35^{* * *}$ \\
\hline Not Stated vs. Overweight & - & $1.30^{* *}$ & - & 1.16 \\
\hline Not Stated vs. Obese & - & 1.11 & - & 0.99 \\
\hline Underweight (ref) vs. Overweight & - & 0.79 & - & $0.49^{* *}$ \\
\hline Underweight vs. Obese & - & 0.67 & - & $0.42^{* * *}$ \\
\hline Overweight (ref) vs. Obese & - & 0.85 & - & 0.85 \\
\hline
\end{tabular}

${ }^{*} \mathrm{P}<0.05{ }^{* *} \mathrm{P}<0.01{ }^{* * *} \mathrm{P}<0.001$. Bolded type denotes significance of at least $<0.05$.

a Odds ratios are shown for binary logistic regressions adjusting for sex, age, site and BMI (except for grade 5-8).

${ }^{\mathrm{b}}$ The $\mathrm{R}^{2}$ value presented is a Nagelkerke $\mathrm{R}^{2}$.

${ }^{c}$ Grades 5-8 only have data available from PEI and Quebec site locations.

${ }^{\mathrm{d}} \mathrm{BMI}$ was unavailable in grade 5-8 students.

\section{Eating at a fast-food place or restaurant}

Among grade 5-8 students, males $(\mathrm{p}<0.001)$, and older students $(\mathrm{p}=0.023)$ were more likely to consume food at a fast-food place or restaurant. The model run with students in grades 9-12 revealed the same pattern for sex $(\mathrm{p}<0.001)$ and age $(\mathrm{p}<0.001)$. With regards to site, students in PEI $(\mathrm{p}<0.001)$, Hamilton $(\mathrm{p}<0.001)$, and Thunder Bay $(\mathrm{p}<0.001)$ were more likely to consume fast-food than those in Quebec. There were no significant correlations with respect to BMI.

\section{Eating in front of the television}

In the model with students in grades 5-8 no values were significant. In the model with students in grades 9-12, males were more likely than females to eat in front of the television $(p=0.009)$. Additionally, those in those in PEI $(p<0.001)$, Hamilton $(p<0.001)$, and Thunder Bay $(\mathrm{p}<0.001)$ were more likely than students in Quebec to eat in front of the television. Those in Hamilton were also more likely than those in PEI to eat in front of the television $(p=0.006)$. Obese students were also more likely than underweight $(\mathrm{p}=0.014)$, healthy weight $(\mathrm{p}=$ 0.026), and those who did not state their height and weight $(p=0.004)$ to eat in front of the television.

Models were run for each of the four dichotomized eating behavior outcomes to compare students in grade 5-8 with those in grade 9-12. Students in grade 9-12 were less likely to eat breakfast $(\mathrm{OR}=0.61, \mathrm{p}<0.001)$, and eat with an adult family member $(\mathrm{OR}=0.69, \mathrm{p}<0.001)$ than those in grade 5-8. Those in grade 9-12 were more likely to eat at a fast-food place or restaurant $(\mathrm{OR}=1.58$, $\mathrm{p}<0.001)$, and eat in front of the television $(\mathrm{OR}=1.18$, $\mathrm{p}<0.001$ ) than those in grade $5-8$.

\section{Discussion}

The current study examined patterns of eating behaviors among a large sample of Canadian youth. The findings indicate that almost one third of students in grades 5 to 
Table 5 Correlates of eating behaviors (fast-food \& television)

\begin{tabular}{|c|c|c|c|c|}
\hline & \multicolumn{2}{|c|}{ Fast-food place or restaurant } & \multicolumn{2}{|c|}{ Eating in front of the TV } \\
\hline & Grade $5-8^{a}$ & Grade $9-12^{a}$ & Grade $5-8^{a}$ & Grade $9-12^{a}$ \\
\hline Adjusted $\mathrm{R}^{2 \mathrm{~b}}$ & 0.005 & 0.031 & 0.001 & 0.020 \\
\hline \multicolumn{5}{|l|}{ Sex } \\
\hline Female (ref) vs. Male & $1.27^{* * *}$ & $1.42^{* * *}$ & 1.07 & $1.16^{* *}$ \\
\hline Age & $1.05^{*}$ & $1.11^{* * *}$ & 1.00 & 1.00 \\
\hline \multicolumn{5}{|l|}{ Site } \\
\hline PEI (ref) vs. Quebec ${ }^{c}$ & 0.98 & $0.65^{* * *}$ & 0.92 & $0.65^{* * *}$ \\
\hline PEI vs. Hamilton & - & $1.25^{* *}$ & - & $1.23^{* *}$ \\
\hline PEI vs. TBay & - & 0.89 & - & 1.11 \\
\hline Quebec (ref) vs. Hamilton & - & $1.94^{* * *}$ & - & $1.89^{* * *}$ \\
\hline Quebec vs. TBay & - & $1.37^{* * *}$ & - & $1.71^{* * *}$ \\
\hline Hamilton (ref) vs. TBay & - & 0.71 & - & 0.90 \\
\hline \multicolumn{5}{|l|}{$\mathrm{BMI}^{\mathrm{d}}$} \\
\hline Healthy Weight (ref) vs. Underweight & - & 0.77 & - & 0.71 \\
\hline Healthy Weight vs. Overweight & - & 0.95 & - & 1.04 \\
\hline Healthy Weight vs. Obese & - & 1.14 & - & $1.35^{*}$ \\
\hline Healthy Weight vs. Not Stated & - & 0.97 & - & 0.90 \\
\hline Not Stated (ref) vs. Underweight & - & 0.80 & - & 0.79 \\
\hline Not Stated vs. Overweight & - & 0.98 & - & 1.15 \\
\hline Not Stated vs. Obese & - & 1.17 & - & $1.50^{* *}$ \\
\hline Underweight (ref) vs. Overweight & - & 1.23 & - & 1.45 \\
\hline Underweight vs. Obese & - & 1.47 & - & $1.89^{*}$ \\
\hline Overweight (ref) vs. Obese & - & 1.20 & - & 1.31 \\
\hline
\end{tabular}

${ }^{*} \mathrm{P}<0.05{ }^{* *} \mathrm{P}<0.01{ }^{* * *} \mathrm{P}<0.001$. Bolded type denotes significance of at least $<0.05$.

${ }^{a}$ Odds ratios are shown for binary logistic regressions adjusting for sex, age, site and BMI (except for grade 5-8).

${ }^{\mathrm{b}}$ The $\mathrm{R}^{2}$ value presented is a Nagelkerke $R^{2}$.

'Grades 5-8 only have data available from PEl and Quebec site locations.

${ }^{\mathrm{d}} \mathrm{BMI}$ was unavailable in grade 5-8 students.

8 and one half of grades 9-12 students skipped breakfast at least once per week. These estimates are higher than US data collected between 1999 and 2006 from the National Health and Nutrition Examination Survey, in which $20 \%$ of $9-13$ year olds and $32 \%$ of $14-18$ year olds reported skipping breakfast [34]. Additional research is required to examine whether the higher prevalence of breakfast skipping in the current study reflects differences between geographic regions or a change in trends over time. Present day breakfast skipping may indicate increased busyness in the morning, or a conscious effort to avoid eating breakfast.

Slightly more than half of students in grade 9-12 from the current study reported eating with family members 5 or more times per week, while a review from 2008 indicated that between $25 \%-57 \%$ of adolescents eat meals with family members this often [9]. One Canadian study found the prevalence of engaging in family meals every night to be $62 \%$, but this data was from a single city, whereas the current study used a larger sample across multiple regions, which may offer greater representativeness [11]. Another Canadian study in 2005 using students from Nova Scotia found the prevalence of eating family meals 5 or more times per week to be $59 \%$ among grade 5 students, compared to $68 \%$ in the current study for grade 5-8 students [35].

Results from the current study revealed that $18 \%$ of students in grade $5-8$, and $27 \%$ of those in grade $9-12$ ate fast-food twice per week or more. Canadian data from 2009 estimated that 38\% of youth aged 13-23 consume fast-food twice a week or more [36]. The current study's results are slightly lower than expected. American data suggests that $75 \%$ of teenagers consume fast-food at least once a week, compared to estimates in the current study of $55 \%$ of students in grade $5-8$, and $70 \%$ in grade 9-12 eating at a fast-food place or restaurant once a week or more [37]. These data indicate a lower consumption of fast-food in Canada versus America among the youth population, and a lower prevalence than previously thought among Canadian data. 
The findings indicate that $16 \%$ of students in grade 5-8 and 9-12 ate meals in front of the television 5 times per week or more. This estimate is similar to previous data collected in Canada, but significantly less than in the US, in which estiamtes have ranged from 30\% to $64 \%$ of youth who report eating in front of the TV on a daily basis $[24,27,38]$. One possible reason for this may be a fundamental difference in the way Canadians and Americans view meal times. Canadians may place more importance on having conversations during meal times, and not bringing media to the dinner table.

To our knowledge, no other study has examined differences in these four eating behaviors across various geographic regions in Canada. Considering how distinct the survey locations were, the results across regions were strikingly similar, with a few notable exceptions. Students in Quebec were more likely than other regions to eat with an adult family member, and consume breakfast. One possible reason for increased breakfast consumption in certain regions may be due to the presence of breakfast programs. However, it is unclear based on the number of programs offered in each Province, and the population size, whether this is the case. Breakfast clubs of Canada has 297 programs in Quebec, including club des petits dejeuners du Quebec. PEI only has one breakfast program, and Ontario has 386, 51 of which are in the Hamilton region, and 31 are in the Northwest (which includes Thunder Bay) [39]. Other reasons for a higher prevalence of these behaviors in Quebec may be related to a culture that values family meal time.

The results from the current study indicate that youth who are obese are less likely to eat breakfast than students who have a healthy weight. Findings from past research indicates that skipping breakfast is associated with weight gain $[4,5,40]$. Diet quality was not examined in this study, so it is unclear whether this is the mechanism through which not eating breakfast affects weight status.

Previous research is inconsistent regarding the association between weight status and eating meals with family members. The current study found that students who were obese, overweight, or of a healthy weight were less likely to eat meals with family members than underweight individuals. Eating family meals has been shown to have a positive effect on diet quality, and may increase family connectedness, and health-promoting behaviors [41]. It is unclear from this study whether people who are obese choose to eat less with their family, or whether engaging in fewer family meals leads to obesity possibly through deterioration of diet quality and/or health-promoting behaviors.

The results from the current study are inconsistent with the literature on fast-food consumption among youth: students who were obese were not more likely to consume fast-food than non-obese individuals in the current study [20,21,23]. Previous literature has found an association between consumption of fast-food and obesity. Possible reasons for this discrepancy may be due to the nature of the questions asked in the current study. Participants were asked about the number of times they ate at a fast-food place or restaurant during the week, but it is unclear what type of food they were consuming and the nutritional value of this food. Additionally, the analysis in the current study examined patterns of weekday consumption (Monday to Friday); weekend consumption of fast-food may depict a different pattern.

With respect to watching TV while eating, the current study found that obese students were more likely to engage in this behavior compared to those who were underweight or of a healthy weight, which is consistent with the literature $[24,29]$. Possible reasons for the association between weight status and watching TV while eating include increased exposure to advertisements of unhealthy food which affects purchasing behavior, the presence of television preventing dialogue between families about healthy eating practices, and mindless eating in front of the television resulting in larger portions consumed $[24,26]$.

Differences in the four eating behaviors emerged between age groups; older students (grade 9-12) were less likely to eat breakfast, and eat meals with at least one adult family member. Breakfast consumption may decrease with age for a variety of reasons such as lack of time, or to intentionally decrease caloric intake. Eating meals with family members may lessen as a student gets older due to lack of compatibility with adults' schedules, or increased autonomy. Older students were also more likely to eat at a fast-food place or restaurant. Adolescence is a time for fostering independence which may be exerted by purchasing one's own food, likely fast-food for its convenience and low price [42]. Older students were also more likely to eat meals in front of the television. Possible reasons for this include a lack of parental presence during meal-time or a greater interest in media-related activities than the younger age group.

Certain gender differences in the current study were inconsistent with past research. A study by NeumarkSztainer and colleagues found that males were more likely to eat with family members than females [43]. Among all ages in the current study there were no differences between sexes with respect to eating with an adult family member.

The present study found that males were more likely to consume food at a fast-food place or restaurant, and eat while watching TV (only among grade 9-12 students), a finding that is consistent with past data $[17,18,25]$. The 
current study also found that females were more likely than males to skip breakfast among all age ranges, which is consistent with past Canadian, and International research $[34,44]$. Possible reasons include weight and/or body image concerns; girls are more likely to engage in dieting practices that involve calorie restriction and meal skipping [34,44]. Research suggests however that this is an ineffective dieting practice, as people who skip breakfast are more likely to overeat later in the day [6].

\section{Strengths and limitations}

This study exhibits several strengths. It boasts a large sample size drawn from four distinct geographical areas. The large sample size of the current study provided considerable power to detect small statistical differences. For example, to detect a bivariate difference in an outcome such as "frequency of eating at a fast food place or restaurant", the current study had sufficient power to detect a $2.4 \%$ difference for a 2 -sided t-test, where $\alpha=.05$ and Beta $=.80$.

In addition, the value of having common measures and indicators cannot be underestimated $[45,46]$. Recent efforts have helped promote more consistent reporting and measurement for youth health [47-50].

In addition to the strengths, the current study has limitations. The current study is cross-sectional in nature, therefore, no causal inferences should be made regarding associations between variables. All analyses are based on self-completed surveys and self-reported data. The limitations of self-reported height and weight have been identified in previous literature [51,52]. However, the measure of height and weight used by SHAPES has been validated and the project has been conducted in over 3000 schools with over 500,000 students since the year 2000. Additionally, with the measures used correlations between self-reported measures of height and weight and actual measures were significant [53]. Another limitation is that even though surveys were anonymous, certain sensitive questions may have been influenced by social desirability bias. For example, students may feel uncomfortable admitting that they consume fast-food every day of the week.

Finally, while most survey items in different regions were consistent, in a few instances, response categories needed to be collapsed to ensure comparability. For example, behaviors of once per week and less than once per week were combined, which decreased the specificity of responses.

\section{Conclusions}

The current study adds to the evidence base on patterns of eating among Canadian youth. Students categorized as obese were significantly more likely to report watching TV while eating, and less like to report eating with an adult family member, and eating breakfast. Future research should focus on identifying trends over time and providing greater insight into the causal associations between eating behaviors and obesity. In addition, the current study found that older students were less likely to eat breakfast, and eat meals with a family member, and more likely to consume fast-food and eat in front of the television. Late adolescence seems to be a critical time for certain eating behaviors, and interventions aimed at promoting healthy behaviors during this time may be beneficial.

\section{Competing interests}

The authors declare that they have no competing interests.

\section{Authors' contributions}

HGL and DH performed data analysis and drafted the manuscript. SM and DM contributed to manuscript preparation. All authors read and approved the final manuscript.

\section{Acknowledgements}

The authors express appreciation for the opportunity to conduct secondary analysis of these data, and to the students and staff at the participating schools for provision of the data. The authors gratefully acknowledge the support of the Prince Edward Island Department of Early Education and Childhood Development and Québec en Forme which paid for data collection. In addition, the Comprehensive School Health Research Group, University of Prince Edward Island, Québec en Forme and Propel Centre for Population Health Impact, University of Waterloo facilitated collection of data. The authors would like to extend thanks to Dana Zummach and Robin Burkhalter for assistance with the manuscript. This research was supported by Ontario Graduate Scholarships (Lillico), the Propel Centre for Population Health Impact, a Canadian Institutes for Health Research New Investigator Award (Hammond), and a Canadian Cancer Society Research Institute Junior Investigator Research Award (Hammond).

\section{Author details}

${ }^{1}$ School of Public Health \& Health Systems, University of Waterloo, 200 University Avenue West, Waterloo, Ontario N2L 3G1, Canada. ${ }^{2}$ Propel Centre for Population Health Impact, University of Waterloo, 200 University Ave West, Waterloo, Canada. ${ }^{3}$ School of Nursing, University of Prince Edward Island, 550 University Ave, Charlottetown, Canada.

Received: 16 May 2013 Accepted: 25 March 2014 Published: 7 April 2014

\section{References}

1. Roberts KC, Shields M, de Groh M, Aziz A, Gilbert J: Overweight and obesity in children and adolescents: results from the 2009 to 2011 Canadian health measures survey. Health Rep 2012, 23(3):3-7.

2. Riediger ND, Shooshtari S, Moghadasian MH: The influence of sociodemographic factors on patterns of fruit and vegetable consumption in Canadian adolscents. J Am Diet Assoc 2007, 107:1511-1518.

3. Tjepkema M: Measured Obesity Adult obesity in Canada: Measured height and weight. Nutrition: Findings from the Canadian Community Health Survey. Ottawa, ON: Statistics Canada; 2008.

4. Berkey CS, Rockett HRH, Gillman MW, Colditz GA: Longitudinal study of skipping breakfast and weight change in adolescents. Int $J$ Obesity (Lond) 2003, 27:1258-1266

5. Niemeier HM, Raynor HA, Lloyd-Richardson EE, Rogers ML, Wing RR: Fastfood consumption and breakfast skipping: predictors of weight gain from adolescence to adulthood in a nationally representative sample. J Adolesc Health 2006, 39:842-849.

6. Ma Y, Bertone ER, Stanek EJ, Reed GW, Herbert JR, Cohen NL, Merriam PA, Ockene IS: Association between eating patterns and obesity in a freeliving US adult population. Am J Epidemiol 2003, 158(1):85-92. 
7. Nicklas TA, Reger C, Myers L, O'Neil C: Breakfast consumption with and without vitamin-mineral supplement Use favorably impacts daily nutrient intake of ninth-grade students. J Adolesc Health 2000, 27:314-321.

8. Merten MJ, Williams AL, Shriver LH: Breakfast consumption in adolescence and young adulthood: parental presence, community context, and obesity. J Am Diet Assoc 2009, 109:1384-1391.

9. Woodruff SJ, Hanning R: A review of family meal influence on Adolescents' dietary intake. Can J Diet Pract Res 2008, 69:14-22.

10. Neumark-Sztainer D, Larson NI, Fulkerson JA, Eisenberg ME, Story M: Family meals and adolescents: what have we learned from project EAT (eating among teens)? Public Health Nutr 2010, 13:1113-1121.

11. Goldfield GS, Murrary MA, Buchholz A, Henderson K, Obeid N, Kukaswadia A, Flament MF: Family meals and body mass index among adolescents: effects of gender. Appl Physiol Nutr Metab 2011, 36:539-546.

12. Taveras EM, Rifas-Shiman SL, Berkey CS, Rockett HR, Field AE, Frazier AL, Colditz GA, Gillman MW: Family dinner and adolescent overweight. Obes Res 2005, 13(5):900-906.

13. Fitzpatrick E, Edmunds LS, Dennison BA: Positive effects of family dinner are undone by television viewing. J Am Diet Assoc 2007, 107:666-671.

14. Garriguet D: Overview of Canadians' Eating Habits. Ottawa: Statistics Canada; 2004:1-47

15. McCrory M, Fuss P, Saltzman E, Roberts SB: Dietary determinants of energy intake and weight regulaton in healthy adults. J Nutr 2000, 130:276S-279S.

16. French S, Story M, Neumark-Sztainer D, Fulkerson JA, Hannan P: Fast food restaurant use among adolescents: associations with nutrient intake, food choices and behavioral and psychosocial variables. Int J Obes 2001, 25(12):1823-1833.

17. Paeratakul S, Ferdinand DP, Champagne CM, Ryan DH, Bray GA: Fast-food consumption among US adults and children: dietary and nutrient intake profile. J Am Diet Assoc 2003, 103:1332-1338.

18. Bowman SA, Gortmaker SL, Ebbeling CB, Pereira MA, Ludwig DS: Effects of fast-food consumption on energy intake and diet quality among children in a national household survey. Pediatricts 2004, 113(1):112-118.

19. Wiecha JL, Finkelstein D, Troped PJ, Fragala M, Peterson KE: School vending machine use and fast-food restaurant use are associated with sugar-sweetened beverage intake in youth. J Am Diet Assoc 2006, 106(10):1624-1630.

20. Fulkerson JA, Farbakhsh K, Lytle L, Hearst MO, Dengel DR, Pasch KE, Kubik MY: Away-from-home family dinner sources and associations with weight status, body composition, and related biomarkers of chronic disease among adolescents and their parents. J Am Diet Assoc 2011, 111:1892-1897.

21. Gillis $\sqcup$, Bar-Or O: Food away from home, sugar-sweetened drink consumption and juvenile obesity. J Am Coll Nutr 2003, 22(6):539-545.

22. Woodruff SJ, Hanning RM, McGoldrick K: The influence of physical and social contexts of eating on lunch-time food intake among southern Ontario, Canada, middle school students. J Sch Health 2010, 80:421-428.

23. Taveras EM, Berkey CS, Rifas-Shiman SL, Ludwig DS, Rockett HR, Field AE, Colditz GA, Gillman MW: Association of consumption of fried food away from home with body mass index and diet quality in older children and adolescents. Pediatrics 2005, 116:e518-e524.

24. Liang T, Kuhle S, Veugelers PJ: Nutrition and body weights of Canadian children watching television and eating while watching television. Public Health Nutr 2009, 12:2457-2463.

25. Marquis M, Filion YP, Dagenais F: Does eating while watching television influence children's food-related behaviors? Can J Diet Pract Res 2005, 66:12-18.

26. Coon KA, Goldberg J, Rogers BL, Tucker KL: Relationships between Use of television during meals and children's food consumption patterns. Pediatrics 2001, 107:E7

27. Feldman S, Eisenberg ME, Neumark-Sztainer D, Story M: Associations between TV during family meals and dietary intake among adolescents. J Nutr Educ Behav 2007, 39:257-263.

28. Blass EM, Anderson DR, Kirkorian HL, Pempek TA, Price I, Koleini MF: On the road to obesity: television viewing increases intake of high-density foods. Physiol Behav 2006, 88(4-5):597-604.

29. Thomson M, Spence JC, Raine K, Laing L: The association of television viewing with snacking behavior and body weight of young adults. Am J Health Promot 2008, 22:329-335.
30. Cameron R, Manske SR, Brown KS, Jolin MA, Murnaghan D, Lovato C: Integrating public health policy, practice, evaluation, surveillance, and research using local data collection and feedback systems: the example of the school health action planning and evaluation system (SHAPES). Am J Public Health 2007, 97(4):648-654.

31. Leatherdale S, Manske S, Wong S, Cameron R: Integrating research, policy, and practice in school-based physical activity prevention programming: the school health action, planning, and evaluation system (SHAPES) physical activity module. Health Promot Pract 2009, 10(2):254-261.

32. Propel Centre for Population Health Impact: School health action, planning and evaluation system. http://www.shapes.uwaterloo.ca.

33. World Health Organization: Growth reference 5-19 years (on-line). http://www.who.int/growthref/who2007_bmi_for_age/en/index.html.

34. Deshmukh-Taskar PR, Nicklas TA, O'Neil CE, Keast DR, Radcliffe JD, Cho S: The relationship of breakfast skipping and type of breakfast consumption with nutrient intake and weight status in children and adolescents: the national health and nutrition examination survey 1999-2006. J Am Diet Assoc. 2010, 110:869-878.

35. Veugelers PJ, Fitzgerald AL: Prevalence of and risk factors for childhood overweight and obesity. CMAJ 2005, 173(6):607-613.

36. Nexopia: Consumption \& perceptions of fast-food a teen perspective. http://static.lamp.nexopia.com/wikis/youth_research/Nexopia_Youth_ Marketing_Research_t_N5.pdf. Accessed May 17, 2012.

37. CBS News: Fast-food teens in All sizes. http://www.cbsnews.com/2100500194_162-623285.html.

38. Kaiser Family Foundation: Generation M: media in the lives of 8-18 year-olds. http://www.kff.org/entmedia/7251.cfm.

39. Breakfast Clubs of Canada: Breakfast programs. Breakfast clubs of Canada. http://www.breakfastclubscanada.org.

40. Timlin MT, Pereira MA, Story M, Neumark-Sztainer D: Breakfast eating and weight change in a 5-year prospective analysis of adolescents: project EAT (eating among teens). Pediatrics. 2008, 121:e638-e645.

41. Contento IR, Williams SS, Michela JL, Franklin AB: Understanding the food choice process of adolescents in the context of family and friends. J Adolesc Health. 2006, 38:575-582.

42. Nestle M: Food politics: how the food industry influences nutrition and health Berkeley, CA: University of California Press; 2002.

43. Neumark-Sztainer D, Hannan PJ, Story M, Croll J, Perry C: Family meal patterns: associations with sociodemographic characteristics and improved dietary intake among adolescents. J Am Diet Assoc. 2003, 103:317-322.

44. Vereecken C, Dupuy M, Rasmussen M, Kelly C, Nansel TR, Al Sabbah H, Baldassari D, Jordan MD, Maes L, Niclasen BV, Ahluwalia N, HBSC Eating and Dieting Focus Group: Breakfast consumption and its socio-demographic and lifestyle correlates in 41 countries participating in the HBSC study. Int J Public Health. 2009, 54:S180-S190.

45. Riley B, Cameron R, Campbell S, Manske S, Lamers-Bellio K, Czukar D: Exploring the use of common measures across jurisdictions to advance knowledge and improve population intervention for chronic disease prevention. Can J Prog Eval 2009, 24(3):39-58.

46. Leatherdale ST: Evaluating school-based tobacco control programs and policies. An opportunity gained and many opportunities lost. Can J Prog Eval. 2009, 24(3):89-106.

47. Kroeker C: Manske S on behalf of Youth Excel. Core Indicators and Measures of Youth Tobacco Control: Indicators and Questions to use with Youth Respondents and/or School Environment Assessments. Waterloo, Ontario: Propel Centre for Population Health Impact, University of Waterloo; 2011.

48. Card A, Kroeker C, Manske S, on behalf of Youth Excel: Core Indicators and Measures of Youth Physical Activity and Sedentary Behaviours: Indicators and Questions to use with Youth Respondents and/or School Environment Assessments. Waterloo, Ontario: Propel Centre for Population Health Impact, University of Waterloo; 2011.

49. Strange K, McKenna M, Naylor PJ on behalf of Youth Excel: Core Indicators and Measures of Youth Nutrition: Indicators and Questions to use with Youth Respondents and/or School Environment Assessments. Waterloo, Ontario: Propel Centre for Population Health Impact, University of Waterloo; 2011.

50. Jamal H, Wong K, Roberts M, Manske S: Youth Population Health Assessment Roundtable Report: Recommendations for Moving Forward. Toronto, Ontario: Public Health Ontario; 2011.

51. Brener ND, McManus T, Galuska DA, Lowry R, Wechsler H: Reliability and Validity of Self-reported Height and Weight Among High School Students. J Adolesc Health 2003, 32:281-287. 
52. Sherry B, Jefferds ME, Grummer-Strawn LM: Accuracy of Adolescent Selfreport of Height and Weight in Assessing Overweight Status. Arch Pediatr Adolesc Med 2007, 161(12):1154-1161.

53. Wong SL, Leatherdale ST, Manske SR: Reliability and validity of a schoolbased physical activity questionnaire. Med Sci Sports Exerc 2006, 38(9):1593-1600

doi:10.1186/1471-2458-14-323

Cite this article as: Lillico et al:: The prevalence of eating behaviors among Canadian youth using cross-sectional school-based surveys. BMC Public Health 2014 14:323.

\section{Submit your next manuscript to BioMed Central and take full advantage of:}

- Convenient online submission

- Thorough peer review

- No space constraints or color figure charges

- Immediate publication on acceptance

- Inclusion in PubMed, CAS, Scopus and Google Scholar

- Research which is freely available for redistribution 